\title{
Mechanism for Aar2p function as a U5 snRNP assembly factor
}

\author{
Gert Weber, ${ }^{1,3}$ Vanessa F. Cristão ${ }^{2,3}$ Flavia de L. Alves, ${ }^{2}$ Karine F. Santos, ${ }^{1}$ Nicole Holton, ${ }^{1}$ \\ Juri Rappsilber, ${ }^{2}$ Jean D. Beggs, ${ }^{2,4}$ and Markus C. Wahl ${ }^{1}$ \\ ${ }^{1}$ Fachbereich Biologie/Chemie/Pharmazie, Abteilung Strukturbiochemie, Freie Universität Berlin, D-14195 Berlin, Germany; \\ ${ }^{2}$ Wellcome Trust Centre for Cell Biology, University of Edinburgh, Edinburgh EH9 3JR, United Kingdom
}

\begin{abstract}
Little is known about how particle-specific proteins are assembled on spliceosomal small nuclear ribonucleoproteins (snRNPs). Brr2p is a U5 snRNP-specific RNA helicase required for spliceosome catalytic activation and disassembly. In yeast, the Aar2 protein is part of a cytoplasmic precursor U5 snRNP that lacks Brr2p and is replaced by Brr2p in the nucleus. Here we show that Aar2p and Brr2p bind to different domains in the C-terminal region of Prp8p; Aar2p interacts with the RNaseH domain, whereas Brr2p interacts with the Jab1/MPN domain. These domains are connected by a long, flexible linker, but the Aar2p-RNaseH complex sequesters the Jab1/MPN domain, thereby preventing binding by Brr2p. Aar2p is phosphorylated in vivo, and a phospho-mimetic S253E mutation in Aar2p leads to disruption of the Aar2p-Prp8p complex in favor of the Brr2p-Prp8p complex. We propose a model in which Aar2p acts as a phosphorylation-controlled U5 snRNP assembly factor that regulates the incorporation of the particle-specific Brr2p. The purpose of this regulation may be to safeguard against nonspecific RNA binding to Prp8p and/or premature activation of Brr2p activity.
\end{abstract}

[Keywords: pre-mRNA splicing; protein interaction; protein phosphorylation; protein structure; spliceosome; yeast] Supplemental material is available for this article.

Received April 24, 2011; revised version accepted June 17, 2011.

Small ribonucleoproteins (RNPs) are major components of several RNA processing machineries in eukaryotic cells, including spliceosomes, which catalyze the removal of noncoding intervening sequences (introns) from precursor messenger RNAs (pre-mRNAs) and the ligation of the neighboring coding regions (exons) to generate mature mRNA. Canonical small nuclear RNPs (snRNPs), such as the U1, U2, U4, and U5 snRNPs of the major spliceosome, contain a set of seven common Sm proteins bound at a uridine-rich $\mathrm{Sm}$ site in the snRNAs, forming the Sm core RNPs (Pomeranz Krummel et al. 2009; Weber et al. 2010). In metazoans, Sm core RNPs are assembled via an elaborate pathway involving nucleo-cytoplasmic shuttling and two multiprotein machineries, the Prmt5 and the SMN complexes (for review, see Kolb et al. 2007; Chari et al. 2009). In addition, each snRNP contains a variable number of particle-specific proteins. The final stages of metazoan snRNP biogenesis are thought to take place in nuclear Cajal bodies, at least in the case of the U2 snRNP (Nesic et al. 2004). However, little is known about how the specific proteins are assembled.

\footnotetext{
${ }^{3}$ These authors contributed equally to this work.

${ }^{4}$ Corresponding author.

E-mail j.beggs@ed.ac.uk.

Article published online ahead of print. Article and publication date are online at http://www.genesdev.org/cgi/doi/10.1101/gad.635911. Freely available online through the Genes \& Development Open Access option.
}

Spliceosomes assemble de novo on the substrate premRNAs by stepwise recruitment of the snRNPs and many additional splicing factors that are not stably associated with snRNPs (for review, see Wahl et al. 2009). During the cycle of assembly, activation, catalysis, and disassembly, the spliceosome is repeatedly remodeled with the help of eight conserved RNA-dependent ATPases/RNA helicases and one G-protein (for review, see Staley and Guthrie 1998). Each remodeling step is associated with changes in the macromolecular composition and in the protein-protein, protein-RNA, and RNA-RNA interaction networks of the spliceosome (Wahl et al. 2009). During the splicing cycle, several snRNPs are also profoundly reorganized. For example, the human U5 snRNP enters the spliceosome as a 20S particle that is part of the U4/U6-U5 tri-snRNP, in which the U4 and U6 snRNAs are extensively base-paired. During spliceosome activation, the U4 and U6 snRNAs are separated and all U4/U6-specific proteins are removed to make U6 snRNA available as part of the active site(s) (Staley and Guthrie 1998; Wahl et al. 2009). Upon catalytic activation, several components of the multiprotein Prp19 complex (the nineteen complex, NTC, in yeast) become stably associated with U5 snRNP. As a consequence, U5 snRNP is released as a 35 S particle from the post-splicing complex, from which the $20 \mathrm{~S}$ form has to be recycled via an unknown pathway (Makarov 
et al. 2002). Thus, snRNP assembly, restructuring, and reassembly are intimately tied to the splicing process itself.

Two distinct forms of U5 snRNP have been characterized in yeast, distinguished by the presence or absence of the Aar2 protein (Gottschalk et al. 2001; Boon et al. 2007). Aar2p was discovered as a factor involved in the splicing of some pre-mRNAs in yeast (Nakazawa et al. 1991). While Aar2p is not required for splicing per se, removal of the protein blocked repeated rounds of splicing in vitro (Gottschalk et al. 2001), suggesting that it could be involved in U5 snRNP or U4/U6-U5 tri-snRNP (re)assembly. More recently, it was shown that the Aar2p-U5 snRNP has a cytoplasmic phase (Boon et al. 2007). In addition to Aar2p and the Sm proteins, it contains the U5specific Prp8 and Snu114 proteins, but it lacks the essential Brr2 helicase (Gottschalk et al. 2001; Boon et al. 2007) that is required for spliceosome activation (Staley and Guthrie 1998) and disassembly (Small et al. 2006). In the nucleus, Aar2p is replaced by Brr2p, which, along with the remaining U5-specific proteins, gives rise to mature U5 snRNP (Boon et al. 2007).

Here, we investigated the structural basis of Aar2p's association with Prp8p and the mechanism by which it regulates U5 snRNP biogenesis in Saccharomyces cerevisiae. We found that Aar2p forms a stable complex with the RNaseH-like domain of Prp8p, and the C terminus of Aar2p sequesters the C-terminal Jab1/MPN domain of Prp8p, which is a major interaction site of Brr2p. Thus, Aar2p directly competes with Brr2p for binding to Prp8p. Aar2p is found to be phosphorylated in vivo, including residue S253. Introduction of a phospho-mimetic mutation in Aar2p at position 253 disrupts the Aar2p-Prp8p interaction and allows Brr2p entry. Our data suggest that Aar2p acts as a phosphorylation-controlled U5 snRNP assembly factor that regulates the interaction of Brr2p, possibly to avoid nonspecific RNA binding by Prp8p and/ or premature activation of Brr2p activity.

\section{Results}

Aar2p stably interacts with the RNaseH-like domain in the C-terminal region of Prp $8 p$

Previous work suggested that Aar2p interacts with a C-terminal region of Prp8p (Boon et al. 2006, 2007), although a direct contact between the proteins was not demonstrated. We tested interaction of full-length Aar2p fused to the LexA DNA-binding domain (in pBTM116) with HA-tagged C-terminal Prp8p fragments fused to the Gal4 activation domain (in pACTII). Prp8p ${ }^{\mathrm{E} 1}$ (residues 1649-2413) includes the RNaseH and Jab1/MPN domains, Prp8p ${ }^{\mathrm{E} 3}$ (residues 2010-2413) includes the Jab1/ MPN domain but lacks most of the RNaseH domain, and Prp8p ${ }^{\text {E3H }}$ (residues 2010-2413) carries two point mutations (Y2037H, I2051T) that increase its interaction with Brr2p (Fig. 1A; van Nues and Beggs 2001). As the Aar2LexA fusion protein alone activated transcription in yeast two-hybrid assays, we tested interactions among the proteins using pull-down assays instead. Aar2-LexAp coprecipitated the $\operatorname{Prp} 8^{\mathrm{E} 1}$ fusion protein but not $\operatorname{Prp} 8 \mathrm{p}^{\mathrm{E} 3}$ or $\operatorname{Prp} 8 \mathrm{p}^{\mathrm{E} 3 \mathrm{H}}$ (Fig. 1B), indicating that Aar2p binds the C-terminal region of Prp8p and that this interaction requires sequence in the E1 fragment between residues 1649 and 2010.

We next used analytical gel filtration analysis to assess the interaction between Aar2-His ${ }_{6} \mathrm{p}$ and fragments of Prp8p, both recombinantly produced in Escherichia coli. Upon mixing individually purified proteins, Aar2- $-\mathrm{His}_{6} \mathrm{p}$ coeluted with Prp8p ${ }^{1836-2413}$ (covering the RNaseH and Jab1/MPN domains; herein referred to as Prp8p ${ }^{\mathrm{CTF}}$ ) at the expected size of a 1:1 complex (Fig. 1C-E). The two proteins could also be coproduced and copurified via three chromatographic steps (Supplemental Fig. S1A), confirming a stable and direct interaction of Aar2-His ${ }_{6} \mathrm{p}$ and Prp $8 \mathrm{p}^{\mathrm{CTF}}$. Similarly, Aar2-His ${ }_{6}$ p stably bound to Prp8p ${ }^{1836-2092}\left(\operatorname{Prp} 8 \mathrm{p}^{\text {RNaseH }}\right)$. While Aar2-His 6 p also comigrated with Prp8 $\mathrm{p}^{2112-2413}$ (Prp8 $\mathrm{p}^{\text {Jab1/MPN }}$, the elution volume was the same as for the individual proteins, showing that Aar2-His ${ }_{6} \mathrm{p}$ does not stably interact with Prp8p $\mathrm{p}^{\mathrm{Jab} 1 / \mathrm{MPN}}$ (Fig. 1F-H). The latter finding was confirmed in a pull-down assay (Supplemental Fig. S1B). Thus, Aar2p binds directly to the $\mathrm{C}$-terminal region of Prp8p, and the RNaseH domain of Prp8p is the primary interaction module for Aar2p.

Crystal structure analysis of Prp $8 p^{C T F^{*}}$, Aar2p, and an Aar2p-Prp $8 p^{\text {RNaseH }}$ complex

To reveal the molecular basis of the Aar2p-Prp8p interaction, we attempted to crystallize the Aar2-His ${ }_{6} \mathrm{p}-$ Prp8p ${ }^{\text {CTF }}$ complex but failed. However, we could elucidate the crystal structure of $\operatorname{Prp} 8^{1836-2397}$ (called $\operatorname{Prp} 8 \mathrm{p}^{\mathrm{CTF}^{*}}$ ) alone, using all data collected up to $3.3 \AA$ resolution in the refinement (Fig. 2A; Supplemental Table S1; Supplemental Fig. S2A). Prp8 ${ }^{\text {CTF }^{\star}}$ lacked 16 amino acids at the $\mathrm{C}$ terminus compared with Prp8p ${ }^{\mathrm{CTF}}$. In that structure, a 60-residue linker between the domains lacked electron density, demonstrating its intrinsic flexibility (Fig. 2A). In the crystal structure, the unstructured linker could bridge various pairs of crystallographically equivalent domains (e.g., a closely interacting pair compared with a pair of domains in an open conformation) (Fig. 2A) and we could not unequivocally attribute a particular pair of domains to the Prp8 $\mathrm{p}^{\mathrm{CTF}^{\star}}$ molecule in our crystals. However, individually produced $\mathrm{RNaseH}$ and Jab1/MPN domains ran as separate entities in gel filtration (Fig. 1C,F). In addition, protease cleavage in the linker of Prp8p ${ }^{\mathrm{CTF}}$ dissected $\mathrm{RNaseH}$ and Jab1/MPN domains that again migrated as individual proteins (Fig. 2B). These data suggest that in solution, Prp8p ${ }^{\text {CTF }}$ adopts an open conformation in which the two domains are disconnected.

As the Aar2-His ${ }_{6} \mathrm{p}-\operatorname{Prp} 8 \mathrm{p}^{\mathrm{RNaseH}}$ complex also failed to crystallize, we suspected additional flexible elements in Aar2-His ${ }_{6} \mathrm{p}$ and subjected the protein to limited proteolysis. Subtilisin cleaved Aar2-His ${ }_{6} \mathrm{p}$ into two fragments of $\sim 18 \mathrm{kDa}$ each, comprising residues 1-159 and 168-324 (Supplemental Fig. S1C). Thus, subtilisin removed an internal loop (residues 160-167) and the C-terminal 31 


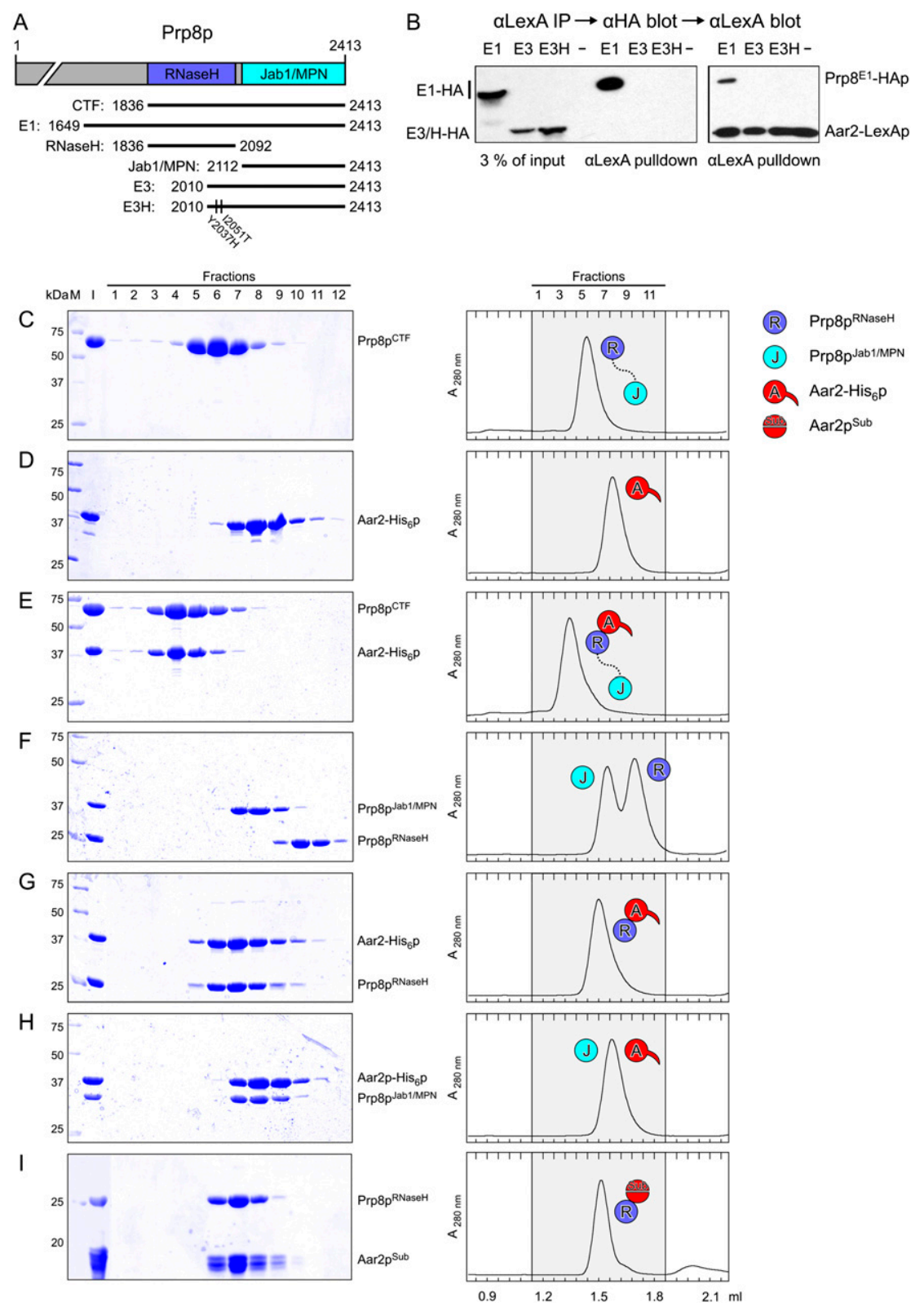

Figure 1. Aar2p-Prp8p interaction. (A) A schematic representation of the Prp8p constructs used in this work. For simplicity, only the RNaseH and Jab1/MPN domains are shown. $(B)$ Aar2-LexAp interacts with Prp8-HAp fragment E1, but not with E3 or E3H. (Left panel) Yeast extracts containing Aar2-LexAp and HA-tagged $\operatorname{Prp} 8 \mathrm{p}^{\mathrm{E} 1}$, $\operatorname{Prp} 8 \mathrm{p}^{\mathrm{E} 3}$, or $\operatorname{Prp} 8 \mathrm{p}^{\mathrm{E} 3 \mathrm{H}}$, or a control with no Prp8 fusion protein (-) were precipitated with anti-LexA antibodies followed by anti-HA Western blot. (Right panel) Subsequent probing with anti-LexA shows that Aar2-LexAp was immunoprecipitated similarly in each case. $(C-I)$ Gel filtration analysis of the indicated proteins or mixtures. (Left) SDS PAGE analysis of eluted fractions (indicated at the top). The first two lanes in each panel show molecular mass standard (M) and the input (I). Numbers on the left indicate the molecular mass of standard proteins in kilodaltons. (Right) Elution profiles. Elution volumes are given at the bottom. Fractions analyzed by SDS PAGE (shaded area) are indicated at the top. $\left(\right.$ Aar $2 \mathrm{p}^{\mathrm{Sub}}$ ) Subtilisin-treated Aar2p. Icons denote proteins and complexes as defined.

amino acids plus the tag of the protein. Gel filtration analysis indicated that the two fragments of subtilisintreated Aar2p (Aar2p ${ }^{\text {Sub }}$ ) remained stably associated. Like full-length Aar2-His ${ }_{6}$ p, Aar2 $\mathrm{p}^{\text {Sub }}$ bound stably to Prp8 $8 \mathrm{p}^{\text {RNaseH }}$ (Fig. 1I) but failed to interact with $\operatorname{Prp} 8 \mathrm{p}^{\text {Jab1/MPN }}$ (data not shown).

Aar2 $\mathrm{p}^{\text {Sub }}$ crystallized alone and in complex with Prp8 $8 \mathrm{p}^{\mathrm{RNaseH}}$. We first solved the structure of the complex by molecular replacement using the structure coordinates of isolated Prp8p ${ }^{\text {RNaseH }}$ (Pena et al. 2008; PDB IDs: $3 \mathrm{E} 9 \mathrm{O}$ and $3 \mathrm{E} 9 \mathrm{P})$. The Aar2 $\mathrm{p}^{\text {Sub }}$ structure was subsequently solved using the coordinates of the Aar $2 \mathrm{p}^{\text {Sub }}$ portion of the complex structure. Both structures were refined to low $R / R_{\text {free }}$ factors with good stereochemistry, using all diffraction data collected to $2.1 \AA$ (Aar2 $\left.\mathrm{p}^{\mathrm{Sub}}\right)$ and
$1.8 \AA$ (Aar2 $^{\text {Sub_Prp8p }} \mathrm{p}^{\mathrm{RNaseH}}$ complex) resolution (Supplemental Table S1; Supplemental Fig. S2B,C).

Prp $8 p^{\text {RNaseH }}$ grasps Aar $2 p^{\text {Sub }}$ between its thumb and fingers

Aar2 $\mathrm{p}^{\text {Sub }}$ is organized in two globular domains, connected via a flexible loop between residues 153 and 171, part of which was cleaved during subtilisin treatment (Figs. 3A; Supplemental Figs. S2D, S3). The two domains interact closely via an extensive hydrophobic interface $153 \%$ nonpolar atoms) that buries $1504 \AA^{2}$ of combined surface area (Supplemental Fig. S2E), explaining why they remained stably associated after subtilisin treatment. The $\mathrm{N}$-terminal domain (NTD) contains a 10-stranded, mixed $\beta$ sandwich with three helices surrounding the upper rim. 
Weber et al.
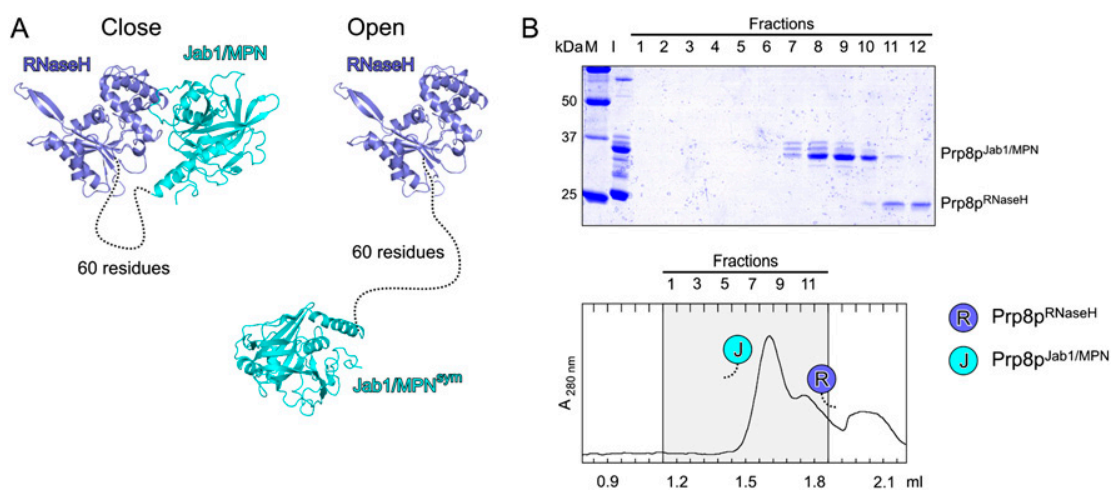

Figure 2. Structure of $\operatorname{Prp} 8 \mathrm{p}^{\mathrm{CTF}^{\star}}$ in isolation. (A) Two possible (close and open) configurations of Prp8 $\mathrm{p}^{\mathrm{CTF}^{\star}}$. (Blue) Prp8 $\mathrm{p}^{\mathrm{RNaseH}}$; (cyan) Prp8p $\mathrm{p}^{\mathrm{Jab} 1 / \mathrm{MPN}}$; (dashed line) flexible linker. Two crystallographically related Jabl/MPN domains are shown with respect to the same RNaseH domain. Other, primarily open, configurations in which the distances between the domains could be bridged by the linker can be found with other symmetryequivalent Jab1/MPN domains. (B) Gel filtration analysis of $\operatorname{Prp} 8 \mathrm{p}^{\mathrm{CTF}}$ after treatment with trypsin. Details and labeling are as in Figure 1, C-I. After treatment with trypsin, the separated domains elute as isolated molecules, indicating that they do not stably interact in solution (cf. Fig. 1F).

The C-terminal domain (CTD) shows an all-helical fold with nine $\alpha$ helices, a $\pi$ helix, and three $3_{10}(\eta)$ helices. Residues 319-324 were not seen in the electron density of either Aar2 $\mathrm{p}^{\text {Sub }}$ alone or in the complex with Prp $8 \mathrm{p}^{\mathrm{RNaseH}}$.

As previously seen in the isolated protein (Pena et al. 2008; Ritchie et al. 2008; Yang et al. 2008), the Prp8p portion in the complex adopts a central mixed $\alpha / \beta$ fold reminiscent of RNaseH-like enzymes, with a long $\beta$-hairpin insertion (residues 1859-1875) and an additional C-terminal $\alpha$-helical domain (Fig. 3A). Globally, Prp8p ${ }^{\text {RNaseH }}$ resembles a mitten with the RNaseH-like core representing the palm, the $\beta$-hairpin insertion representing the thumb, and the helical appendage corresponding to the fingers. The fingers and thumb contact Aar $2 p^{\text {Sub }}$ through two discontinuous interfaces (I and II) with a large gap above the palm region in between (Fig. 3A). At interface $\mathrm{I}$, the tip of the $\operatorname{Prp} 8 \mathrm{p}^{\mathrm{RNa} \text { NeH }}$ fingers (formed by the C terminus of helix H6 of Prp8 $\mathrm{p}^{\mathrm{RNaseH}}$ ) interacts with both Aar $2 \mathrm{p}^{\text {Sub }}$ domains primarily via hydrogen bonds and ionic interactions (Fig. 3C, left). At interface II, the thumb of Prp $8 p^{\text {RNaseH }}$ latches onto one side of the Aar2p ${ }^{\text {Sub }}$ CTD, running along a cleft between helices $\alpha 10$ and $\alpha 13$ with polar interactions dominating the upper part and hydrophobic interactions prevailing in the lower part of the contact (Fig. 3C, right).

Of the combined surface area, $772 \AA^{2}$ is buried upon complex formation. An extended electronegative surface patch on Aar2 $p^{\text {Sub }}$ at interface II and across the gap faces a similarly extensive electropositive surface area on the thumb and palm of Prp8p $\mathrm{p}^{\mathrm{RNaseH}}$ (Fig. 3B). The association of Aar2 $\mathrm{p}^{\text {Sub }}$ with Prp8 $\mathrm{p}^{\mathrm{RNaseH}}$ has hallmarks of a facultative interaction, since large parts of the interfaces are hydrophilic (30\% nonpolar atoms) and thus compatible with exposure to the aqueous environment. Indeed, the surface areas of the proteins facing each other across the gap are blanketed with water molecules (Fig. 3D).

The structure of Aar2 $\mathrm{p}^{\text {Sub }}$ in isolation is very similar to the Prp8p $\mathrm{p}^{\mathrm{RNaseH}}$-bound structure (root-mean-square deviation [RMSD] of $0.92 \AA$ for $289 \mathrm{C} \alpha$ atoms) (Supplemental Fig. S2F, left), with significant adjustments only in the loop between strands $\beta 5$ and $\beta 6$ (NTD) and in the neighborhood of helices $\eta 3$ and $\alpha 11$ (CTD). While the $\beta 5-\beta 6$ loop undergoes an approximate rigid body movement, the region between helices $\eta 3$ and $\alpha 11$ is structurally rearranged upon complex formation (Supplemental Fig. S2G). Similarly, there are only limited changes in the Prp $8 \mathrm{p}^{\text {RNaseH }}$ structure upon interaction with Aar2 $\mathrm{p}^{\mathrm{Sub}}$, which entail small rigid body movements of the thumb and the tip of the fingers toward each other to grasp Aar2p ${ }^{\text {Sub }}$ in between (Supplemental Fig. S2F, right).

Part of the Aar $2 p^{\text {Sub }}-$ Prp $8 p^{\text {RNaseH }}$ interaction resembles cargo binding by vesicular transport adaptors

Comparison of the Aar2p $\mathrm{p}^{\text {Sub }}$ structure to known structures in the Protein Data Bank (http://www.pdb.org) revealed the NTD as a novel fold. Although it resembles diverse proteins with similar $\beta$ sandwiches, no other protein has analogous interspersed helices. The CTD of Aar $2 p^{\text {Sub }}$ is most similar to the domain of Pcf11p that binds Ser2-phosphorylated heptad repeats of the C-terminal tail of RNA polymerase II $(Z$-score $=7.4, \operatorname{RMSD} 3.6 \AA$ for $112 \mathrm{C} \alpha$ atoms) and to the related families of VHS and ENTH domains known from Golgi-ER transport adaptors and endocytic adaptor proteins, respectively $(Z$-score $=$ 7.0 to the VHS domains of human GGA1 and GGA3; RMSD $3.7 \AA$ for $111 \mathrm{C} \alpha$ atoms; Fig. 3E). The helical stack of the CTD also resembles armadillo repeat proteins such as $\beta$-catenin or importin- $\beta$, posing the question of whether Aar2p may act as a transport adaptor for pre-U5 snRNP during nucleo-cytoplasmic shuttling. However, Prp8p has its own nuclear localization signal (Boon et al. 2007).

VHS domain proteins bind acidic cluster-dileucine motifs of their cargo proteins between two helices in an extended conformation (Fig. 3F; Misra et al. 2002; Shiba et al. 2002). This mode of cargo binding resembles the binding of the thumb region of $\operatorname{Prp} 8 \mathrm{p}^{\mathrm{RNaseH}}$ to the CTD of Aar $2 \mathrm{p}^{\text {Sub }}$, although the atomic contacts differ in detail;

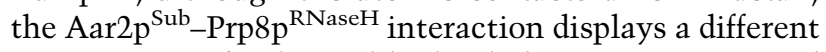
arrangement of polar and hydrophobic interactions, and amino acids from both strands of the Prp $8 \mathrm{p}^{\mathrm{RNa} \text { a }} \beta$ hairpin bind to Aar2 $\mathrm{p}^{\text {Sub }}$. In contrast, Pcf11p binds Ser2phosphorylated RNA polymerase II heptad repeats on the 

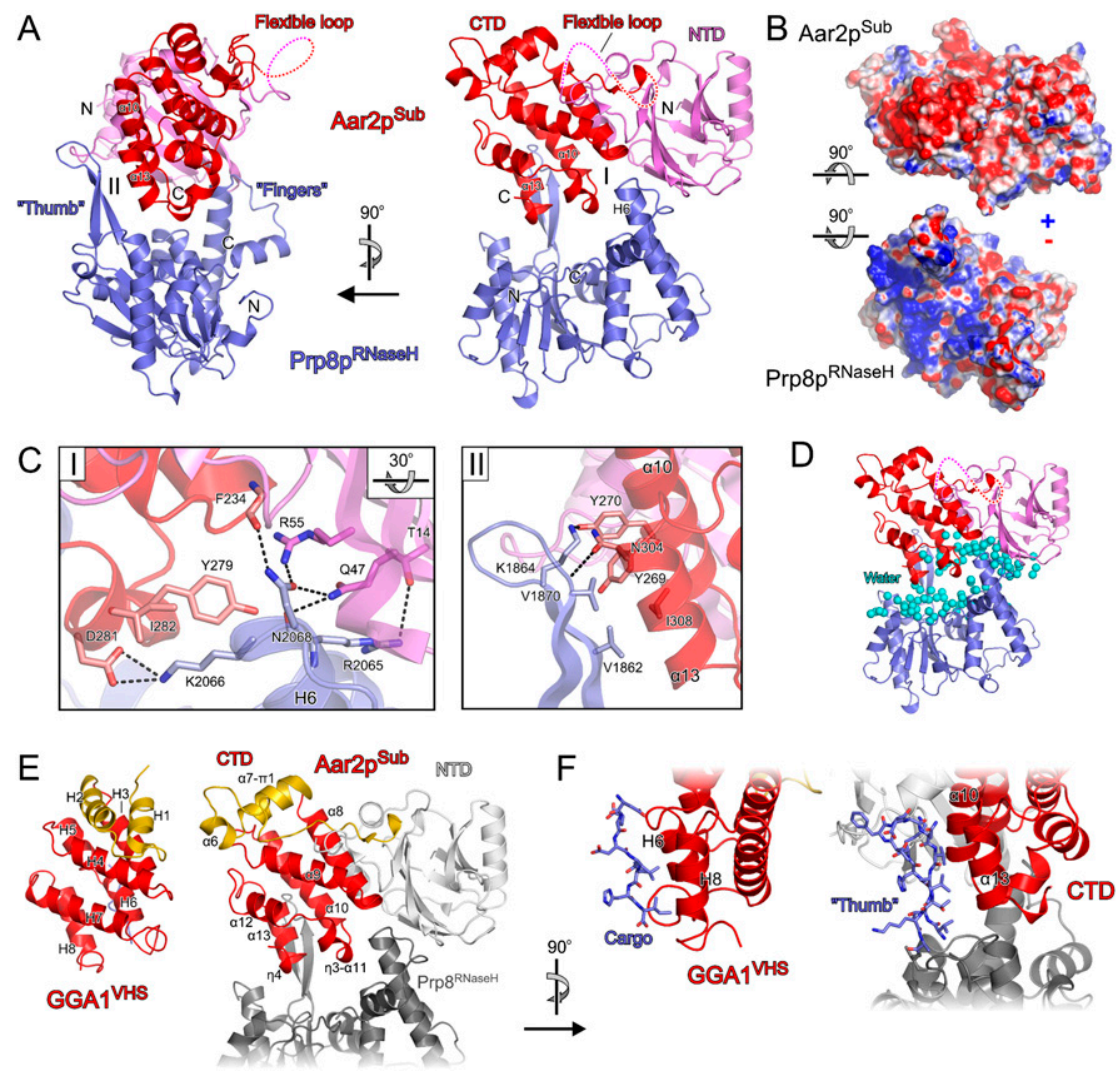

Figure 3. Structure of the Aar2 $\mathrm{p}^{\mathrm{Sub}_{-}}$ Prp8p ${ }^{\text {RNaseH }}$ complex. (A) Orthogonal views on the Aar2 $\mathrm{p}^{\text {Sub_Prp8 }} \mathrm{p}^{\text {RNaseH }}$ complex structure. (Violet) Aar2p $\mathrm{p}^{\mathrm{Sub}} \mathrm{NTD}_{\text {; }}$ (red) CTD; (dashed line) flexible linker between the domains; (blue) Prp8p $\mathrm{p}^{\mathrm{RNaseH}}$. Protein termini, selected secondary structure elements, and the $\operatorname{Prp} 8 \mathrm{p}^{\mathrm{RNaseH}}$ thumb and finger elements are labeled. Roman numerals indicate the two discontinuous interfaces formed upon complex formation. $(B)$ Book view onto the interacting surfaces of Aar2 $\mathrm{p}^{\text {Sub }}$ and Prp $8 \mathrm{p}^{\text {RNaseH }}$. Rotations of the domains relative to the right view in $A$ are indicated by symbols. Surfaces are colored according to electrostatic potential. (Blue) Positive charge; (red) negative charge. (C) Close-up views on interfaces I lleft; rotated $30^{\circ}$ about the horizontal axis as indicated compared with the right panel of A) and II (right; same view as in the left panel of $A$ ). Selected interacting residues are shown as sticks, colored by atom type, and labeled: carbon (as for the respective protein), nitrogen (blue), and oxygen (red). Dashed lines indicate hydrogen bonds or salt bridges. (D) Water molecules (cyan spheres) blanketing the surfaces bordering the central gap in the Aar2p $\mathrm{p}^{\text {Sub_Prp8p }} \mathrm{p}^{\text {RNaseH }}$ complex. $(E)$ Side-by-side view of the human GGA1 VHS domain (left) (Shiba et al. 2002; PDB ID: 1JWG) and the Aar2p ${ }^{\text {Sub }}$ CTD (right). The N-terminal two helices (H1 and $\mathrm{H} 2$ in GGA1 ${ }^{\mathrm{VHS}} ; \alpha 6$ and $\alpha 7-\pi 1$ in Aar2 $\mathrm{p}^{\mathrm{Sub}}$ ) are shown in gold and are positioned differently relative to the remainder of the domains (red). The NTDs of Aar2 $\mathrm{p}^{\mathrm{Sub}}$ and Prp8 $\mathrm{p}^{\mathrm{RNaseH}}$ are shown in light and dark gray, respectively. Proteins and selected secondary structure elements are labeled. $(F)$ Comparison of cargo binding by the GGA1 VHS domain (left) with the interaction of the thumb region of $\operatorname{Prp} 8 \mathrm{p}^{\mathrm{RNaseH}}$ with the Aar2 $\mathrm{p}^{\text {Sub }}$ CTD (right). Cargo peptide and the thumb, respectively, are bound in an elongated conformation between two helices (H6 and H8 in GGA1 ${ }^{\text {VHS }} ; \alpha 10$ and $\alpha 13$ in Aar2p ${ }^{\text {Sub }}$ CTD). Ligand peptide and the Prp8p ${ }^{\text {RNaseH }}$ thumb are shown as sticks and colored by atom type as in $C$. Proteins and selected structural elements are labeled.

opposite side of its VHS-like domain (Meinhart and Cramer 2004).

\section{Aar2p directly competes with Brr2p binding at the Prp $8 p$ C-terminal region by sequestering the Jab1/MPN domain}

A number of studies have shown that Brr2p also interacts with the C-terminal region of Prp8p (van Nues and Beggs 2001; Liu et al. 2006; Pena et al. 2007), and it was reported that more Aar2p associates with Prp8p in cells producing less Brr2p (Boon et al. 2007). We therefore investigated whether Aar2p and Brr2p bind competitively to Prp8p. Gel filtration analysis revealed that Brr2p formed a stable complex with Prp8p ${ }^{\text {CTF }}$ (Fig. 4A,B). However, unlike Aar2p, Brr2p interacted stably with Prp8 $\mathrm{p}^{\text {Jab1/MPN }}$ but not with Prp8p ${ }^{\text {RNaseH }}$ (Fig. 4C).

Despite the preferred open structure of isolated Prp8p $\mathrm{p}^{\mathrm{CTF}}$, which might permit concomitant binding of both Aar2p and Brr2p, we could not assemble a ternary Aar2-His ${ }_{6} \mathrm{p}-\mathrm{Prp} 8 \mathrm{p}^{\mathrm{CTF}}-\mathrm{Brr} 2 \mathrm{p}$ complex. Mixing the three proteins stoichiometrically produced primarily a binary Aar2-His ${ }_{6}$ p-Prp8p ${ }^{\text {CTF }}$ complex and free Brr2p (Fig. 4D).
Increasing amounts of Brr2p led to formation of a mixture of binary Brr2p-Prp8p $\mathrm{p}^{\mathrm{CTF}}$ and Aar2-His ${ }_{6} \mathrm{p}-\mathrm{Prp} 8 \mathrm{p}^{\mathrm{CTF}}$ complexes but were not able to displace Aar2-His 6 p quantitatively (Supplemental Fig. S4).

These findings could be explained if a preformed Aar2$\mathrm{His}_{6} \mathrm{p}-\mathrm{Prp} 8 \mathrm{p}^{\mathrm{RNaseH}}$ complex sequestered the Jab1/MPN domain, making it unavailable for Brr2p. This idea is consistent with the observation that a transposon insertion in the C-terminal Jab1/MPN domain of Prp8p (at residue 2173) interfered with Aar2p binding to U5 snRNP (Boon et al. 2006), suggesting an involvement of the Jab1/MPN domain in Aar2p binding to Prp8p. Indeed, we observed that addition of $\operatorname{Prp} 8 \mathrm{p}^{\mathrm{Jab} / \mathrm{MPN}}$ to a preformed Aar2p-Prp8 $\mathrm{p}^{\mathrm{RNaseH}}$ complex assembled a ternary complex, as revealed in gel filtration (Fig. 4F) and by GST pull-down assays (Fig. 5A, lanes 22,23). Unlike fulllength Aar2p, a Aar2 $\mathrm{p}^{\text {Sub }}$-Prp8 $\mathrm{p}^{\mathrm{RNaseH}}$ complex did not bind Prp8p $p^{\text {Jab1/MPN }}$ (Fig. 4, cf. F and G).

The very $\mathrm{C}$ terminus of Aar2p, not contained in our crystal structures, is well conserved among Aar2p orthologs (Supplemental Fig. S3). To test the importance of this C-terminal tail for binding of $\operatorname{Prp} 8 \mathrm{p}^{\mathrm{jab} 1 / \mathrm{MPN}}$, we generated Aar2 ${ }^{\Delta \mathrm{C}}$-His ${ }_{6}$ p lacking only the last 23 amino acids, but, in 
Weber et al.

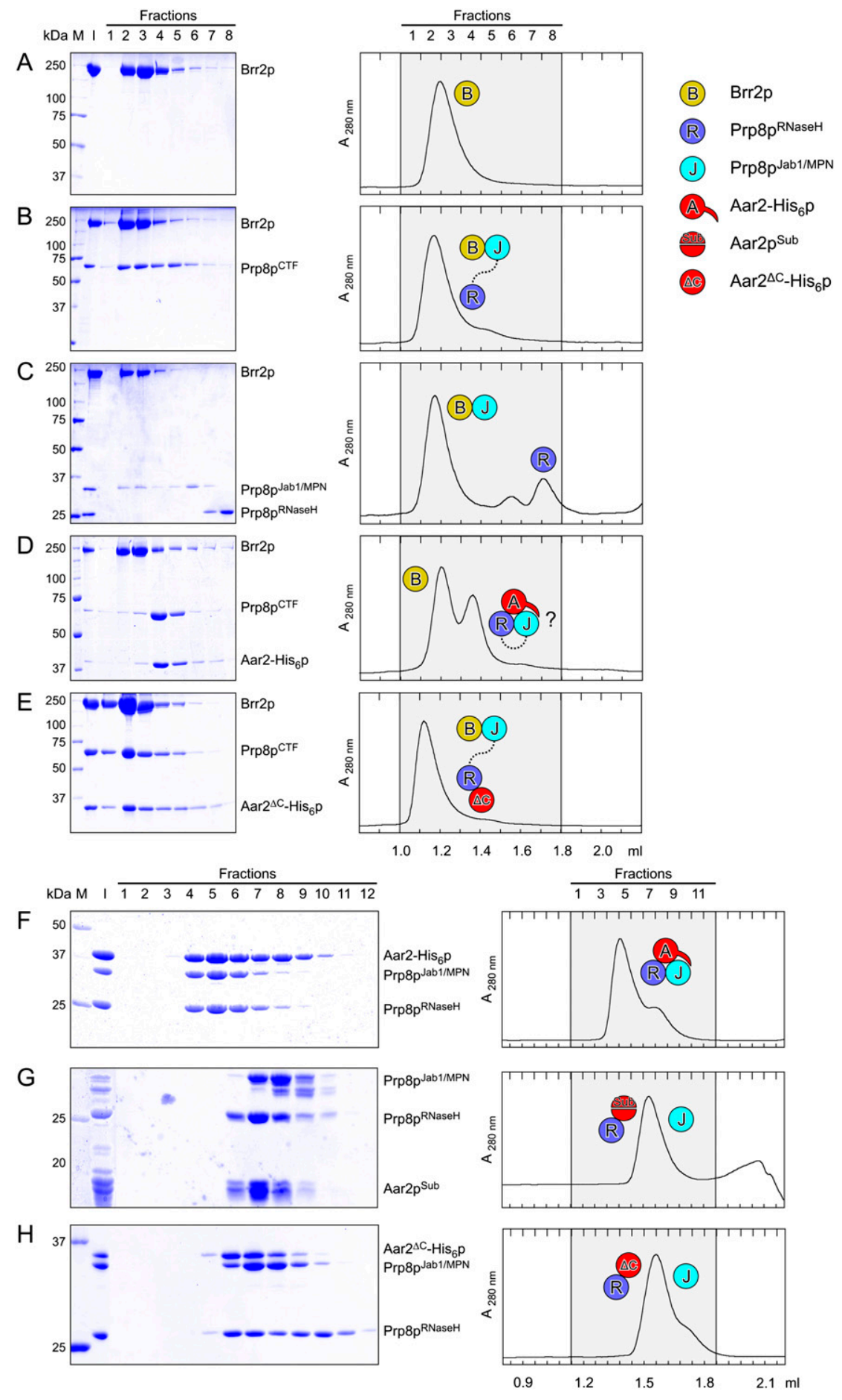

Figure 4. Brr2p-Prp8p interaction and modulation by Aar2p. $(A-E)$ Gel filtration analysis of Brr2p-Prp8p interactions. Details and labeling are as in Figure 1, C-I. Brr2p $(A)$ comigrates with Prp8p ${ }^{\text {CTF }}(B)$ and Prp8p $\mathrm{p}^{\text {Jabl/MPN }}$ $(C)$ but not Prp8p ${ }^{\mathrm{RNaseH}}(C) .(C)$ No ternary complex Brr2p-Prp8p $\mathrm{p}^{\mathrm{RNaseH}}-\operatorname{Prp} 8 \mathrm{p}^{\mathrm{Jab} 1 / \mathrm{MPN}}$ is formed. $(D)$ Primarily free Brr2p and the binary Aar2-His ${ }_{6} \mathrm{p}-\mathrm{Prp} 8 \mathrm{p}^{\mathrm{CTF}}$ complex form upon mixing Brr2p, Aar2-His ${ }_{6} \mathrm{p}$, and Prp8 $\mathrm{p}^{\mathrm{CTF}}$; therefore, the Prp8 $\mathrm{p}^{\text {Jabl/MPN }}$ domain may be unavailable to Brr2p (indicated by question mark [?]). (E) Since the Aar2 ${ }^{\Delta \mathrm{C}}$-His $_{6}$ p still binds the Prp8p RNaseH domain but does not sequester the Jab1/MPN domain (see $H$ ), the latter remains available for binding Brr2p, allowing formation of a ternary complex. $(F-H)$ Gel filtration analysis of Aar2p-Prp8p interactions. Details and labeling are as in Figure 1, C-I. $(F)$ Aar2-His 6 p sequesters Prp8 $\mathrm{p}^{\text {Jab1/MPN }}$ after formation of an Aar2His $_{6} \mathrm{p}-\mathrm{Prp} 8 \mathrm{p}^{\mathrm{RNaseH}}$ complex. Aar2 $\mathrm{p}^{\mathrm{Sub}}$ Prp8 $\mathrm{p}^{\text {RNaseH }}(G)$ or Aar2 ${ }^{\Delta \mathrm{C}}-\mathrm{His}_{6} \mathrm{p}-\mathrm{Prp} 8 \mathrm{p}^{\mathrm{RNaseH}}$ (H) complexes are not able to sequester the Prp8 $\mathrm{p}^{\text {Jab1/MPN }}$ domain, showing that Prp8 $\mathrm{p}^{\mathrm{RNaseH}}$ and the C-terminal tail of Aar2p are required to bind $\operatorname{Prp} 8 \mathrm{p}^{\mathrm{Jab} 1 / \mathrm{MPN}}$. contrast to Aar2p $\mathrm{p}^{\mathrm{Sub}}$, retaining the flexible loop between

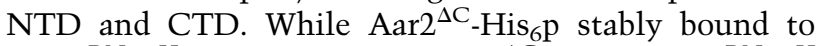
Prp $8 p^{\text {RNaseH }}$, the preformed Aar2 ${ }^{\Delta C}-\mathrm{His}_{6} \mathrm{p}-\operatorname{Prp} 8 \mathrm{p}^{\mathrm{RNaseH}}$ complex failed to bind Prp8p $\mathrm{p}^{\text {Jab1/MPN }}$ (Fig. 4H). Furthermore, unlike full-length Aar2-His ${ }_{6} \mathrm{p}$, Aar2 ${ }^{\Delta \mathrm{C}}-\mathrm{His}_{6} \mathrm{p}$ allowed formation of a ternary Aar2 ${ }^{\Delta C_{-}}-H_{1}{ }_{6} p_{-}-\operatorname{Prp} 8 p^{C T F}$ Brr2p complex, showing that in the Aar2 ${ }^{\Delta \mathrm{C}}-\mathrm{His}_{6} \mathrm{p}-$ Prp8p ${ }^{\text {CTF }}$ complex, the Jab1/MPN domain remains avail- able for binding to Brr2p (Fig. 4E). These data support a model in which Aar2p bound to the RNaseH domain provides a binding platform for the Jab1/MPN domain. The C-terminal 23 amino acids of Aar2p are required for stable sequestration of $\operatorname{Prp} 8 \mathrm{p}^{\mathrm{Jab} 1 / \mathrm{MPN}}$ and competition with Brr2p.

Prp8p residues involved in interface I with Aar2p (Fig. $3 \mathrm{C}$, left) belong to a region (residues 2033-2067) in which 

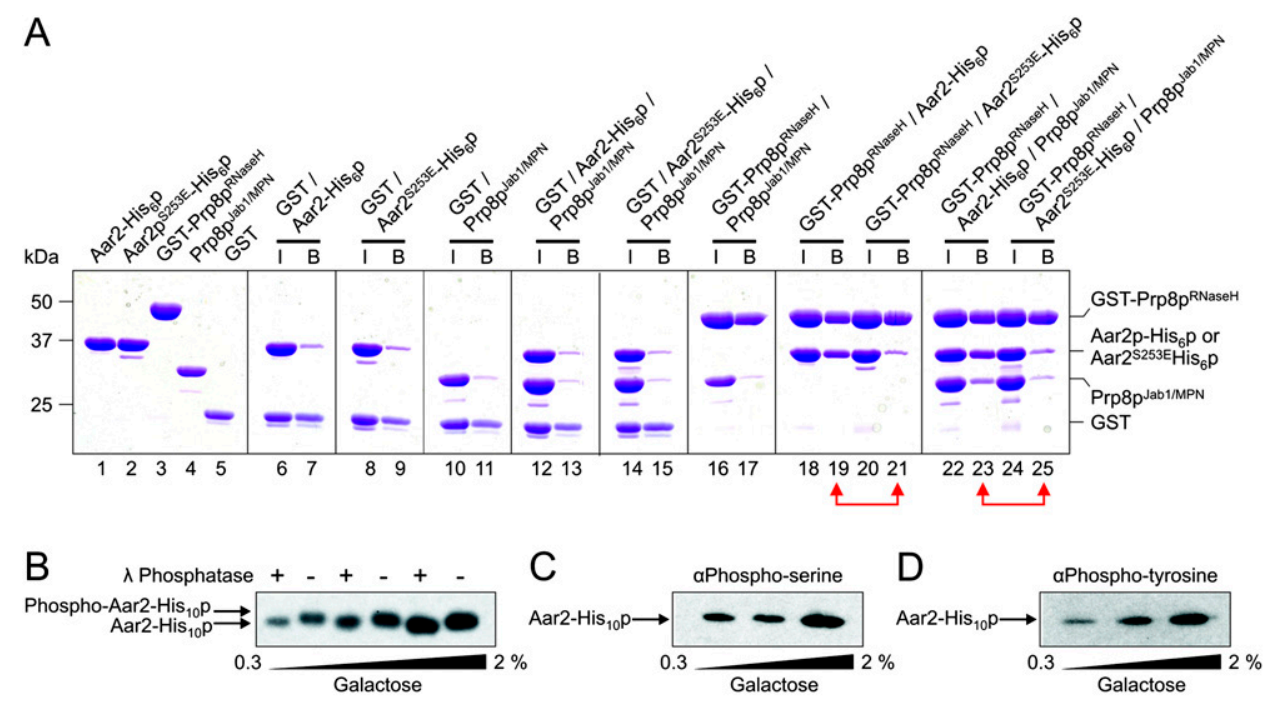

$E$ aLexA IP $\rightarrow \alpha \mathrm{HA}+\alpha \operatorname{Prp} 8$ Western blot
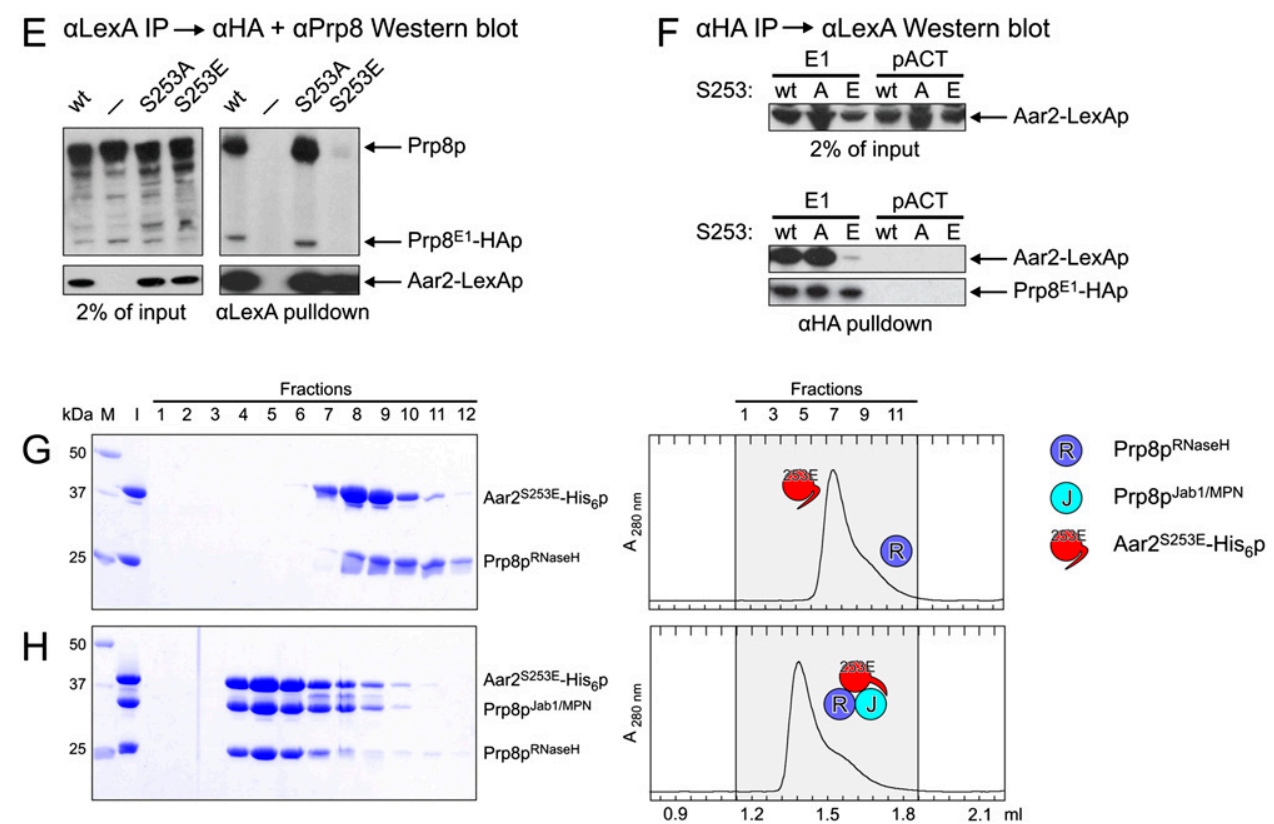

Figure 5. Aar2p is phosphorylated. (A) SDS PAGE analysis of Aar2p-Prp8p interactions by GST pull-down. All experiments were analyzed on the same gel. Numbers on the left indicate the molecular mass of standard proteins (M) in kilodaltons. (I) Mixture added to the glutathione sepharose; (B) pulled-down (bead) fraction. Proteins or protein mixtures added to the beads are identified $a b o v e$ the gel. Red double arrows connect pull-downs of wild-type Aar2-His 6 p compared with Aar2 ${ }^{\mathrm{S} 253 \mathrm{E}}{ }_{-\mathrm{His}_{6}}$ p. GST-Prp8p ${ }^{\mathrm{RNaseH}}$ brought down significantly reduced amounts of Aar2 ${ }^{\mathrm{S} 253 \mathrm{E}}-\mathrm{His}_{6} \mathrm{p}$ (lane 21) compared with wild-type Aar2-His ${ }_{6} \mathrm{p}$ (lane 19). Similarly, significantly less Prp8 $\mathrm{p}^{\text {Jab1/MPN }}$ was brought down by GST-Prp8 $\mathrm{p}^{\text {RNaseH }}$ in the presence of Aar2 ${ }^{\text {S253E }_{2}}$ His $_{6} \mathrm{p}$ (lane 25) compared with wild-type Aar2-His 6 P (lane 23). (B) Phosphatase treatment indicates that Aar2p is phosphorylated. AGY8 cells were grown in different concentrations of galactose to induce Aar2-His ${ }_{10}$ p production to increasing levels. After incubation of extracts with $\mathrm{Ni}^{2+}$-NTA beads, the precipitated Aar2-His ${ }_{10}$ p was treated with $\lambda$ phosphatase $(+)$ or not $(-)$ as recommended by the manufacturer (New England Biolabs), fractionated by SDS PAGE, blotted, and probed with anti-Aar2 antibody (R5725). (C,D) Aar2p has phosphorylated serine(s) and tyrosine(s) in vivo. Aar2His $_{10}$ p produced as in $A$ was analyzed by SDS PAGE, blotted, and probed with anti-phospho-serine $(\mathrm{mAb}$ p5747, Sigma) $(C)$ or antiphospho-tyrosine (mAb 42H4; New England Biolabs) $(D)$ antibodies. $(E, F)$ The S253E variant of Aar2p does not interact with Prp8p. (E) Extracts from yeast cells producing $\operatorname{Prp} 8^{\mathrm{El}}$-HAp and wild-type, S253A, or S253E variants of Aar2-LexA fusion protein or with only LexAp (-) were immunoprecipitated with anti-LexA antibodies. Western blot with anti-HA and anti-Prp8 ( $\alpha 8.6)$ (Boon et al. 2006) antibodies shows that Aar2 $\mathrm{p}^{\mathrm{S} 253 \mathrm{E}}$ pulls down neither full-length Prp8p nor Prp8 ${ }^{\mathrm{E} 1}$-HAp. The blot was reprobed with anti-LexA antibody, showing efficient pull-down of Aar2-LexAp. $(F)$ Extracts from yeast cells producing Prp8 ${ }^{\mathrm{E} 1}$-HAp or with Gal4AD-HAp (pACT) control as well as wild-type, S253A, or S253E variants of the Aar2-LexA fusion protein were immunoprecipitated with anti-HA antibodies, blotted, and probed with anti-LexA, indicating that $\operatorname{Prp} 8^{\mathrm{E} 1}$-HAp interacts with Aar2-LexAp wild type and with S253A, but not with S253E. Reprobing with anti-HA antibody verified that $\operatorname{Prp} 8^{\mathrm{E} 1}-\mathrm{HAp}$ was efficiently immunoprecipitated in the three extracts. $(G, H)$ Gel

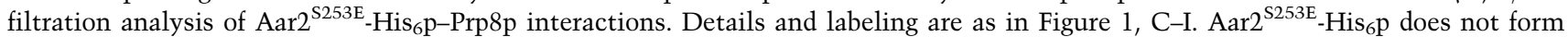
a stable complex with Prp8 $\mathrm{p}^{\mathrm{RNaseH}}(G)$, but addition of Prp8 $\mathrm{p}^{\text {Jab1/MPN }}$ rescues the ternary complex in gel filtration $(H)$. 
amino acid substitutions led to enhanced interaction with Brr2p (van Nues and Beggs 2001). In light of the present Aar2 $\mathrm{p}^{\text {Sub }}$-Prp8 $8 \mathrm{p}^{\mathrm{RNaseH}}$ structure, the direct competition between Aar2p and Brr2p for Prp8p suggests that this phenotype may be explained in part by reduced binding of Aar2p and thus easier access of Brr2p to Prp8p.

\section{Aar2p is phosphorylated in vivo}

In search of a mechanism that would allow replacement of Aar2p by Brr2p to form functional U5 snRNP, we speculated that post-translational modification of Aar2p might regulate the Aar2p-Prp8p interaction. To test whether Aar2 $\mathrm{p}$ is phosphorylated in vivo, extracts from AGY8 yeast cells $\left(P_{G A L 1}: A A R 2-H\right.$ is $\left._{10}\right)$ were treated with $\lambda$ phosphatase, which dephosphorylates phospho-serine (pSer), phospho-threonine (pThr), and phospho-tyrosine (pTyr) residues, the most frequently phosphorylated amino acids in eukaryotes (Zhuo et al. 1993). $\lambda$ Phosphatase treatment caused Aar2p to migrate faster than nontreated Aar2p in an SDS denaturing gel (Fig. 5B), indicative of the removal of one or more phosphate groups. In addition, antibodies specific for pSer or pTyr detected Aar2p by Western blotting, with the signal increasing with the amount of Aar2p in the extracts (Fig. 5C,D). However, there was no signal with anti-pThr antibodies.

In order to identify the phosphorylated amino acids in Aar2-His ${ }_{10}$ p, the protein was purified from AGY8 cell extracts, digested with proteases, and analyzed by mass spectrometry (MS). Five phosphorylated residues were found (S253, T274, Y328, S331, and T345) (Supplemental Fig. S3), confirming the immunodetection of pSer and pTyr residues and additionally detecting pThr residues, possibly due to superior sensitivity of the MS approach.

A multiple sequence alignment of Aar2p orthologs (Supplemental Fig. S3) showed the overall similarity in the sequences $(23.0 \%$ identity and $38.3 \%$ similarity between the budding yeast and human proteins) and the locations of the five phosphorylated amino acids in the C-terminal third of Aar2p. Among those, only S253 is conserved in most organisms, including humans, but not in Arabidopsis thaliana, Caenorhabditis elegans, or Xenopus laevis. Thus, phosphorylation of S253 might be important for a widely conserved function of Aar2p.

The Aar2 $p^{S 253 E}$ phospho-mimetic mutation inhibits binding of Aar2p to Prp $8 p$

To test possible effects of Aar2p phosphorylation on the ability of Aar2p to bind Prp8p and compete with Brr2p, we mutated each of these phosphorylated residues to glutamate (mimicking phosphorylation) or to alanine (preventing phosphorylation) in the Aar2-LexA fusion protein, and tested the effect of these mutations in pulldown assays. Strikingly, the wild-type Aar2-LexA fusion protein and all of the mutant variants, except S253E, brought down endogenous Prp8p and the Prp8 ${ }^{\mathrm{E} 1}$ fusion protein, whereas the S253E mutant protein reproducibly did not coprecipitate either protein (Figs. 5E; Supplemental Fig. S5A,B). Likewise, Prp8p ${ }^{\text {E1 }}$ pulled down the S253A mutant and wild-type Aar2-LexA fusions but not the
S253E variant (Fig. 5F). Furthermore, the smaller S253D phospho-mimetic substitution behaved like S253E (data not shown). These results show that the S253E or S253D phospho-mimetic substitutions inhibit interaction of Aar2p with Prp8p.

We also investigated the growth phenotypes of yeast strains overproducing the interacting proteins. Coproduction of the Aar2-LexA fusion protein and $\operatorname{Prp} 8 \mathrm{p}^{\mathrm{E} 3}$ was slightly detrimental to growth at low temperature, and the coproduction of Aar2-LexAp and Prp8p ${ }^{\mathrm{E} 3 \mathrm{H}}$ was even more so (Supplemental Fig. S5C). These results suggest that the C-terminal E3 and E3H fragments of Prp8p, containing the Jab1/MPN domain, might sequester Brr2p, preventing it from functioning normally. As the growth inhibition depended on the coproduction of the Aar2LexA fusion (data not shown), the effect of sequestering Brr2p might be exacerbated by the excess Aar2p competing with endogenous Brr2p for binding to Prp8p. Mutating the S253 residue in the Aar2-LexA fusion protein to alanine or glutamate gave opposite effects, with S253A slightly exacerbating and S253E slightly suppressing the growth defect (Supplemental Fig. S5C). Thus, the inability of Aar2p with the S253E substitution to interact with Prp8p in vivo alleviates the growth inhibition caused by overproduction of the $\operatorname{Prp} 8^{\mathrm{E} 3}$ or $\operatorname{Prp} 8^{\mathrm{E} 3 \mathrm{H}}$ proteins, supporting a model in which Aar2p competes with Brr2p for binding to Prp8p, unless residue S253 is phosphorylated.

We also tested whether the S253E mutation has a direct effect on binding of Aar2p to Prp8p in vitro. In GST pulldown assays, a strongly reduced amount of Aar2 ${ }^{\mathrm{S} 253 \mathrm{E}}$. His $_{6}$ p was brought down by GST-Prp $8 \mathrm{p}^{\mathrm{RNaseH}}$ compared with wild-type Aar2-His 6 p (Fig. 5A, lanes 18-21), and the fraction of $\operatorname{Prp} 8 \mathrm{p}^{\mathrm{Jab} 1 / \mathrm{MPN}}$ pulled down with GST$\operatorname{Prp} 8 \mathrm{p}^{\mathrm{RNaseH}}$ in the presence of $\mathrm{Aar}^{\mathrm{S} 253 \mathrm{E}}-\mathrm{His}_{6} \mathrm{p}$ was similarly reduced compared with wild-type Aar2-His 6 p (Fig. 5A, lanes 22-25). These data show that binding of Aar2 ${ }^{\mathrm{S} 253 \mathrm{E}_{-}}-\mathrm{His}_{6} \mathrm{p}$ to Prp8p is strongly reduced compared with wild-type Aar2-His 6 p, and that this effect is exerted primarily through a reduced interaction with the Prp8p RNaseH domain. In analytical gel filtration, Aar2 ${ }^{\mathrm{S} 253 \mathrm{E}}-\mathrm{His}_{6} \mathrm{p}$ separated from Prp8 $8 \mathrm{p}^{\mathrm{RNaseH}}$ (Fig. 5G), but in the gentler conditions of this assay, addition of the Prp $8 p^{\text {Jab1/MPN }}$ fragment rescued the ternary complex (Fig. 5H). Similarly, in the reductionist in vitro system, Brr2p was not able to quantitatively titrate Prp8p ${ }^{\mathrm{CTF}}$ from Aar2 ${ }^{\mathrm{S} 253 \mathrm{E}}$-His $_{6} \mathrm{p}$. However, reproducibly more Prp8p ${ }^{\text {CTF }}$ was associated with Brr2p in the presence of Aar2 ${ }^{\mathrm{S} 253 \mathrm{E}}-\mathrm{His}_{6} \mathrm{p}$ compared with wild-type Aar2-His 6 p (Supplemental Fig. S5D,E). These results qualitatively agree with the in vivo pull-down data but suggest that additional factors may be involved in regulating the Aar2p-Prp8p interaction in vivo.

The Aar2 $p^{S 253 E}$ phospho-mimetic mutation allows binding of Brr2p to Prp $8 p$ and leads to conformational changes in Aar2p

In order to investigate the effect of the Aar2p mutants on the ability of Prp8p to bind to Brr2p in vivo, extracts from cells producing wild-type or mutant Aar2-LexA fusions were incubated with anti-Prp8 antibodies. Endogenous 
Prp8p interacted with wild-type Aar2p as well as with the S253A mutant, but not with the S253E mutant protein (Figs. 6A; Supplemental Fig. S5F). Concomitantly, the amount of Prp8p-associated Brr2p increased in extract containing the S253E variant of the Aar2-LexA protein (Fig. 6A,B; Supplemental Fig. S5F). These results are consistent with the idea that phosphorylation of Aar2p at $\mathrm{S} 253$ (mimicked by Aar2 $\mathrm{p}^{\mathrm{S} 253 \mathrm{E}}$ ) reduces Aar2p affinity for Prp8p, allowing Brr2p to interact with Prp8p.

S253 lies directly C-terminal of helix $\alpha 9$ in the Aar2p CTD (Fig. 6C). Its side chain hydroxyl engages in a direct hydrogen bond to the backbone carbonyl of L249. Clearly, conformational adjustments would be required to accommodate a phosphate group on S253 and similar conformational rearrangements are expected upon replacement of S253 with the larger, negatively charged glutamate or aspartate. In the present conformation, the larger side chains would lead to steric clashes and the negatively charged moieties would face a hydrophobic pocket formed by F183, L205, and L249. The structural changes are expected to affect the relative positioning of the first segment of the VHS-like domain, encompassing helices $\alpha 6, \alpha 7$, and $\pi 1$, which lie on top of S253 (Fig. 6C). Such conformational changes may explain how S253 phosphorylation can affect binding of $\operatorname{Prp} 8 \mathrm{p}^{\mathrm{RNaseH}}$, which occurs remote from the $\mathrm{S} 253$ position (Fig. 6C).

Indeed, when subjected to comparative limited proteolysis as a measure of conformational differences,

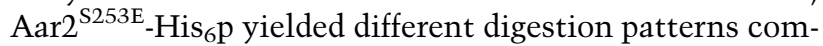
pared with wild-type Aar2-His ${ }_{6} \mathrm{p}$ with a number of proteases tested. For example, upon treatment with trypsin, fragments of $\sim 24-\mathrm{kDa}, 20-\mathrm{kDA}$, and $18-\mathrm{kDa}$ as well as several smaller fragments were observed with both mutant and wild-type proteins, but these fragments appeared at lower trypsin concentrations with the mutant protein, which also gave rise to a novel band at $\sim 22 \mathrm{kDa}$ (Supplemental Fig. S6A).

Circular dichroism (CD) spectra of Aar2-His ${ }_{6} \mathrm{p}$ and Aar2 ${ }^{\mathrm{S} 253 \mathrm{E}}-\mathrm{His}_{6} \mathrm{p}$ reproducibly showed small differences (Supplemental Fig. S6B), indicating some minor changes in the secondary structure contents (calculated from CD: $35.3 / 33.2 \%$ helix, $18.3 / 17.8 \% \quad \beta$ strand for wild-type/ S253E Aar2-His 6 ; crystal structure of Aar2 $\mathrm{p}^{\text {Sub }}$ relative to full-length: $33.5 \%$ helix, $15.2 \% \beta$ strand). CD melting profiles showed that both proteins exhibit cooperative unfolding with a similar melting temperature $\left(46.1^{\circ} \mathrm{C}-\right.$ $46.5^{\circ} \mathrm{C}$ ) for the main transition (Supplemental Fig. S6C). Reproducibly, wild-type Aar2-His 6 p showed a second minor transition above $60^{\circ} \mathrm{C}$. Qualitatively, these results are in line with differences in the protease digestion pattern and suggest that upon phosphorylation at S253, Aar2p would undergo a limited conformational change, which most likely affects the VHS-like domain and possibly the C-terminal tail, and that this structural change leads to reduced affinity for Prp8p.

\section{Discussion}

\section{Assembly of snRNPs depends on chaperones} and recycling factors

Assembly of functional macromolecular complexes is a challenging task in the crowded cellular environment and is frequently assisted by trans-acting factors (for review, see Chari and Fischer 2010). Among such factors, assembly chaperones associate with subunits or partial complexes to promote the formation of native-like subassemblies, prevent the formation of unproductive interactions, and/or avoid premature contacts. Frequently, assembly chaperones impose kinetic or thermodynamic traps that have to be resolved by the action of additional
A $\quad$ aPrp8 IP $\rightarrow$

$\alpha \operatorname{LexA}+\alpha B$ rr2 + aPrp8 Western blot
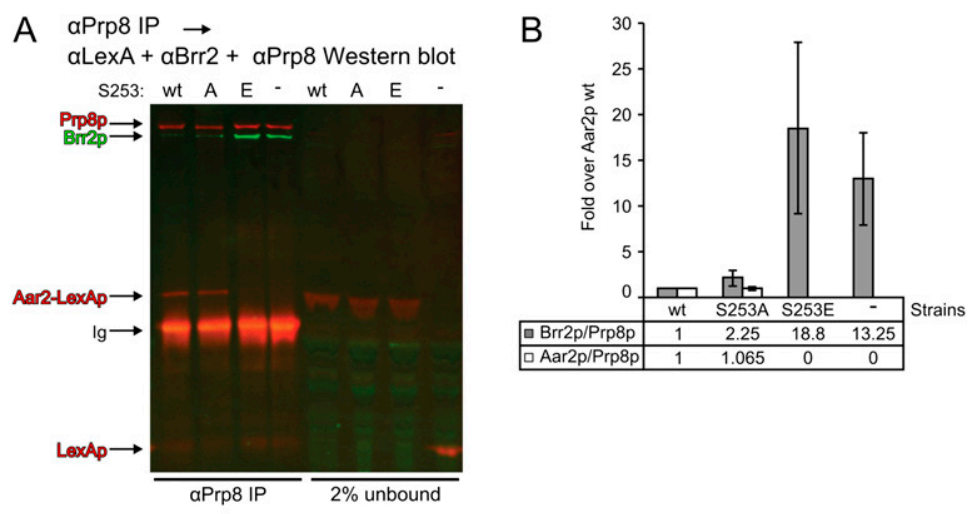

C

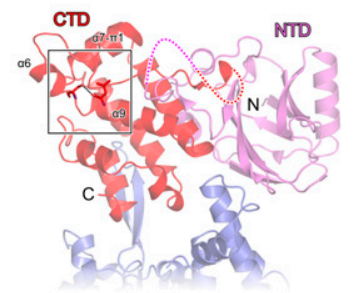

Figure 6. Influence of Aar2p and variants on the Brr2pPrp8p interaction. $(A, B)$ Prp8p interacts with more Brr2p when bound by less Aar2p (S253E). (A) Full-length Prp8p was immunoprecipitated from yeast cell extracts containing the highly expressed wild-type, S253A, or S253E variants of Aar2-LexAp, or with LexAp as a control; blotted; and probed with rat anti-Brr2, rabbit antiLexA, and rabbit anti-Prp8 primary antibodies, followed by goat anti-rat IRDye 680LT and donkey anti-rabbit IRDye $800 \mathrm{CW}$ secondary antibodies. The results were visualized and quantified using a LI-COR Odyssey imaging system. $(B)$ Average ratios of precipitated Brr2p/Prp8p and Aar2p/Prp8p are shown for two experiments. Error bars indicate the maximum and minimum values obtained. A similar analysis was also performed in triplicate using detection by standard Western blot (see Supplemental Fig. S5F). (C) Positioning of S253 in the Aar2p $\mathrm{p}^{\text {Sub }}-\operatorname{Prp} 8 \mathrm{p}^{\mathrm{RNaseH}}$ complex structure. (Left) Structural overview. The region surrounding Aar2p S253 is boxed. Protein termini, domains, and selected secondary structure elements are labeled. (Right) Closeup view of the boxed region. Selected residues are shown as sticks and colored by atom type as in Figure 3C. (Dashed line) Hydrogen bond. 
assembly factors. Furthermore, different assembly steps often take place in different cellular or subcellular compartments. These principles are nicely illustrated in the biogenesis of Sm core RNPs in metazoans /Chari and Fischer 2010). However, it is presently unknown to what extent and how the de novo assembly of snRNP-specific proteins is also regulated.

Continued pre-mRNA splicing requires snRNP recycling and reassembly, since several snRNPs are compositionally and structurally remodeled during the splicing process (Wahl et al. 2009). As the Sm core RNPs apparently remain intact during the splicing cycle, the main task in recycling of snRNPs may be the reorganization of snRNAs and reassociation of snRNP-specific proteins. While Prp24p and the U6-associated Lsm2-8 protein complex indeed assist reassembly of U4 and U6 snRNAs after each round of splicing (Raghunathan and Guthrie 1998; Verdone et al. 2004), no recycling factors for snRNPspecific proteins have so far been characterized.

Aar2p-an assembly factor for a U5 snRNP-specific protein

Like the U4/U6 di-snRNP, U5 snRNP is also profoundly remodeled during splicing (Makarov et al. 2002). Based on the documented precursor-product relationship between Aar2p-U5 snRNP and mature U5 snRNP in yeast (Boon et al. 2007), and since Aar2p depletion interferes with repeated rounds of splicing in vitro (Gottschalk et al. 2001), we investigated Aar2p as a candidate assembly and recycling factor for U5 snRNP-specific proteins.

We show that Aar2p forms a stable complex with the C-terminal region of the U5-specific Prp8p, binding its $\mathrm{RNaseH}$ domain and sequestering its Jab1/MPN domain via Aar2p's $C$ terminus. It thereby hinders Brr2p from interacting with the Jab1/MPN domain. Our in vitro binding analyses demonstrate that Brr2p alone is inefficient in displacing Aar2p from Prp8p (Supplemental Fig. S4), suggesting that Aar2p imposes a kinetic or thermodynamic trap on U5 snRNP assembly, possibly functioning as an assembly chaperone. Phosphorylation mimicry at residue S253 of Aar2p reduces the affinity of the protein for Prp8p, and our data indicate structural changes in Aar2 $\mathrm{p}^{\mathrm{S} 253 \mathrm{E}}$ compared with wild-type Aar2p. Similar structural changes can be expected upon phosphorylation at position 253. Therefore, a presently unidentified Ser/Thr protein kinase may act as another U5 snRNP assembly factor that overcomes the block imposed by Aar2p. Taken together, our results demonstrate that Aar2p is a veritable U5 snRNP assembly factor, which, unlike previously characterized snRNP assembly factors, is required for the ordered binding of a U5 snRNPspecific protein, Brr2p (Fig. 7). Further experiments will be required to determine whether Aar2p actually functions as a molecular chaperone.

Overexpressed Aar2p or Aar2 $\mathrm{p}^{\mathrm{S} 253 \mathrm{~A}}$ fusion protein greatly reduced the amount of Brr2p bound to Prp8p compared with the control, in which Aar2p is present only at the endogenous level (minus sign [-] in Fig. 6A,B). Thus, the excess Aar2 fusion protein inhibits Brr2p binding to full-length Prp8p. In contrast, overexpressed Aar2p ${ }^{\text {S253E }}$ does not inhibit Brr2p binding to Prp8p and may even facilitate this interaction, as the amount of Prp8p-associated Brr2p was reproducibly greater in the presence of Aar2 $\mathrm{p}^{\mathrm{S} 253 \mathrm{E}}$ than in control extract with no excess Aar2p (Figs. 6B; Supplemental Fig. S5F). By inference, the S253-phosphorylated variant, may have the ability to make Brr2p more accessible to Prp8p, possibly by sequestering an unknown factor that inhibits interaction of Brr2p with Prp8p. For a better understanding of the protein interactions, this should be further studied, with the mutant protein expressed at the endogenous level. Taken together, while our data do not provide ultimate proof of the mechanism of Aar2p/Brr2p exchange, they provide strong evidence for the involvement of an Aar2p kinase.

Although the RNaseH and Jab1/MPN domains of Prp8p do not stably interact in isolation (Fig. 2B), the close

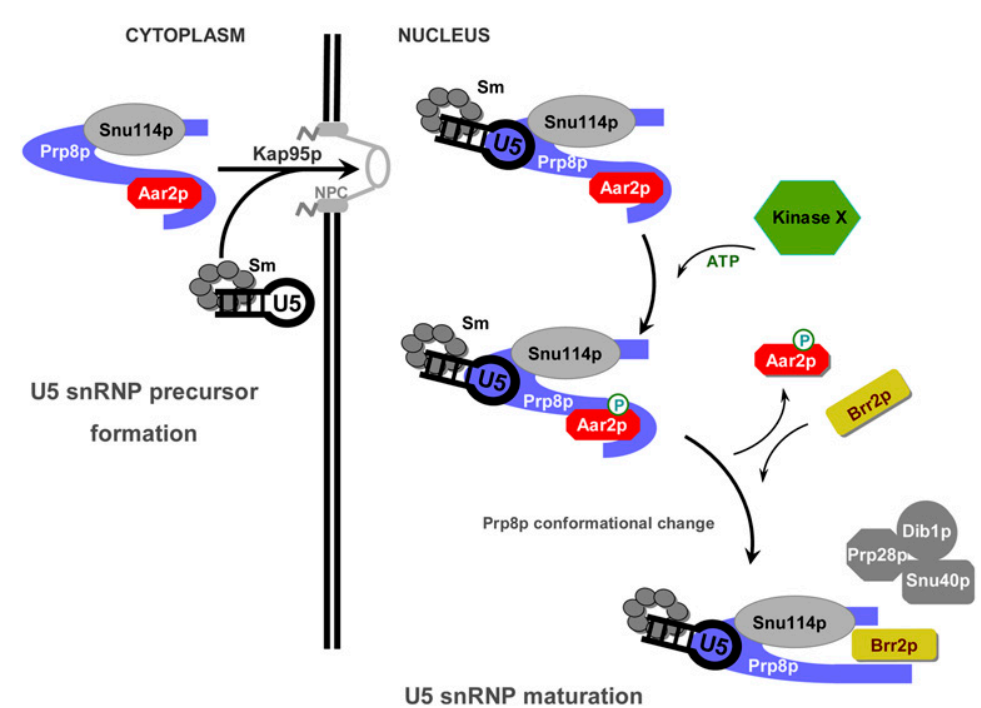

Figure 7. Model for the U5 snRNP maturation. New elements added to the U5 snRNP maturation model proposed by Boon et al. (2007). Aar2p-U5 snRNP is assembled in the cytoplasm and transported to the nucleus. In the nucleus, Aar2p is phosphorylated by an unidentified kinase (Kinase X). Phosphorylated Aar2p exhibits reduced affinity for Prp8p, leaves the pre-U5 snRNP, and allows Brr2p entry. In view of our finding that the $\mathrm{RNaseH}$ and Jabl/MPN domains, which are joined by a flexible linker region, do not interact, we propose that the $\mathrm{C}$ terminus of Prp8p takes on a different conformation when not bound by Aar2p. Additional U5 snRNP proteins lacking from Aar2p-U5 snRNP are presumably assembled concomitantly with Brr2p (Boon et al. 2007). Phosphorylated Aar2p has a possible active role in recruiting Brr2p (not shown). 
configuration of the Prp8 $\mathrm{p}^{\mathrm{CTF}^{\star}}$ fragment (Fig. 2A, left) may still represent a biologically relevant interaction between these domains, which is too weak to survive gel filtration or pull-down assays with the separated domains. The surface of the RNaseH domain that interacts with Aar2p is still accessible in the close conformation of $\operatorname{Prp} 8 \mathrm{p}^{\mathrm{CTF}^{*}}$. Furthermore, the C-terminal $\sim 35$ residues of the Prp8p Jab1/MPN domain, which comprise a putative Brr2-binding region (Pena et al. 2007), are also surface-exposed in the close conformation of $\operatorname{Prp} 8 \mathrm{p}^{\mathrm{CTF}}$. However, since in a combined model the Jab1/MPN C terminus is remote from the Aar2p binding site on the $\mathrm{RNaseH}$ domain (data not shown), additional structural and biochemical studies are required to clarify whether the close conformation of Prp8 $\mathrm{p}^{\mathrm{CTF}^{\star}}$ is relevant for the sequestering of the Jab1/ MPN domain by Aar2p.

\section{Functional significance of the Aar2p-assisted U5 snRNP assembly}

What could be the benefit of the complex Aar2p-mediated U5 snRNP assembly mechanism? Prp8p is an important scaffolding protein at the heart of the spliceosome and interacts with all functional elements of the pre-mRNA, several snRNAs, and other key protein splicing factors (for review, see Grainger and Beggs 2005). Structural and functional analyses of the C-terminal region of Prp8p have suggested that its $\mathrm{RNaseH}$-like domain provides a platform for the handover of the pre-mRNA 5 '-splice site from U1 snRNA to U6 snRNA and may be involved in stabilizing the catalytic RNA network (Pena et al. 2008; Ritchie et al. 2008; Yang et al. 2008). Consistent with a role during spliceosome catalytic activation, the C-terminal region of Prp8p encompassing its $\mathrm{RNaseH}$ and Jab1/MPN domains directly modulates the activity of Brr2p (Maeder et al. 2009; Pena et al. 2009; Zhang et al. 2009).

The C-terminal region of Prp8p directly binds the U4/U6 snRNA duplex (Zhang et al. 2009), and the Prp8p RNaseH-like domain also interacts with other RNAs, including a putative mimic of the catalytic RNA core of the spliceosome (Ritchie et al. 2008). Modeling studies have suggested that the groove between the thumb and fingers of the RNaseH-like domain serves as an RNAbinding site (Pena et al. 2008). Thus, Aar2p binding at the same site, as shown in the present Aar $2 \mathrm{p}^{\text {Sub }}-\operatorname{Prp} 8 \mathrm{p}^{\mathrm{RNaseH}}$ cocrystal structure, may prevent premature binding of the U4/U6 duplex or binding of nonspecific RNAs at this domain during U5 snRNP assembly.

Upon U4/U6-U5 tri-snRNP formation, Brr2p must be regulated to avoid unwinding U4/U6 di-snRNA prematurely. We suggest that Aar2p regulates the incorporation of Brr2p into U5 snRNP in a manner that silences the Brr2p enzymatic activity during U4/U6-U5 tri-snRNP formation. This suggested role of Aar2p is supported by the observation that the $\mathrm{D} 281 \mathrm{~N}$ mutant of yeast $A A R 2$ acts as a suppressor of the temperature-sensitive prp38-1 allele (Pandit et al. 2006) that causes slow release of U1 and U4 snRNAs during catalytic activation (Xie et al. 1998). D281 of Aar2p forms a salt bridge with K2066 of
Prp8p in interface I (Fig. 3C, left), an interaction that is expected to be weakened upon mutation of D281 to an asparagine.

As in vitro experiments have indicated a role for Aar2p in recycling snRNPs during extended splicing reactions (Gottschalk et al. 2001), Aar2p may have a reciprocal function, displacing Brr2p from Prp8p in a post-splicing complex, to facilitate the regeneration of functional U5 snRNPs. Thus, cycles of phosphorylation and dephosphorylation of Aar2p may regulate U5 snRNP assembly and recycling, and identifying the relevant kinase and phosphatase is the next important step in further elucidating the U5 snRNP (re)assembly mechanism.

\section{Materials and methods}

Yeast work

Details of yeast strains and plasmids are provided in Supplemental Tables S2 and S3. For MS analysis, yeast extract was prepared from AGY8 (P $P_{G A L 1}$ :AAR2-His 10$)$ cells grown in $2 \%(\mathrm{w} / \mathrm{v})$ galactose, and Aar2-His $10 \mathrm{p}$ was affinity-purified using $\mathrm{Ni}^{2+}$-NTA beads followed by SDS-PAGE and analyzed as described in the Supplemental Material.

\section{Analysis of recombinant proteins}

All proteins for biochemical, biophysical, and structural studies were from yeast and, except Brr2p, were produced in E. coli and purified to near homogeneity by chromatographic techniques. Brr2p was produced in insect cell culture. Structural integrity was checked by $\mathrm{CD}$ spectroscopy and CD melting analyses. Targets were crystallized by the sitting drop vapor diffusion method, and diffraction data were collected at beamline 14.2 of the BESSY storage ring (Berlin, Germany). The structures were solved by molecular replacement and refined by standard strategies. Details are given in the Supplemental Material.

\section{Database deposition}

Structure coordinates and diffraction data were deposited with the Protein Data Bank (http://www.pdb.org) under accession codes 3SBG (Prp $8^{\mathrm{CTF}^{*}}$ ), 3SBS (Aar2p ${ }^{\text {Sub }}$ ), and 3SBT (Aar2p $\mathrm{pub}_{-}$ $\left.\operatorname{Prp} 8^{\mathrm{RNaseH}}\right)$ and will be released upon publication.

\section{Acknowledgments}

We thank Claudia Kipar, Claudia Alings, and Traudy Wandersleben (Freie Universität Berlin) for help with cloning, expression, protein preparation, in vitro interaction analyses, and crystallization. We acknowledge access to beamline BL14.2 of the BESSY II storage ring (Berlin, Germany) via the Joint Berlin MX-Laboratory, sponsored by the Helmholtz Zentrum Berlin für Materialien und Energie, the Freie Universität Berlin, the Humboldt-Universität zu Berlin, the Max-Delbrück Centrum, and the Leibniz-Institut für Molekulare Pharmakologie. This work was supported by the Deutsche Forschungsgemeinschaft (grants SFB 740/2 and WA 1126/4-1 to M.C.W.) and the Wellcome Trust (grant 087551 to J.D.B.), and benefited from European Commission funding LSGHCT-2005-518238 for the EURASNET Network of Excellence (to J.D.B.). V.F.C. is a predoctoral student of the Gulbenkian $\mathrm{PhD}$ Programme in Biomedicine funded by Scholarship SFRH/BD/ 15854/2005 from the FCT of Portugal. J.D.B. holds the Royal Society Darwin Trust Research Professorship. J.R. is a Senior 
Research Fellow of the Wellcome Trust. G.W., K.F.S., and N.H. prepared and characterized recombinant proteins and conducted interaction studies in vitro. G.W. and M.C.W. carried out the crystallographic analyses and supervised the work performed by K.F.S. and N.H. V.F.C. performed the experiments to identify phosphorylated residues in Aar2p and to characterize the mutant variants of Aar2p in vivo and in yeast extracts. F.A. and J.R. performed the MS analyses. J.D.B. supervised the work performed by V.F.C. J.D.B. and M.C.W. wrote the manuscript.

\section{References}

Boon KL, Norman CM, Grainger RJ, Newman AJ, Beggs JD. 2006. Prp8p dissection reveals domain structure and protein interaction sites. RNA 12: 198-205.

Boon KL, Grainger RJ, Ehsani P, Barrass JD, Auchynnikava T, Inglehearn CF, Beggs JD. 2007. prp8 mutations that cause human retinitis pigmentosa lead to a U5 snRNP maturation defect in yeast. Nat Struct Mol Biol 14: 1077-1083.

Chari A, Fischer U. 2010. Cellular strategies for the assembly of molecular machines. Trends Biochem Sci 35: 676-683.

Chari A, Paknia E, Fischer U. 2009. The role of RNP biogenesis in spinal muscular atrophy. Curr Opin Cell Biol 21: 387-393.

Gottschalk A, Kastner B, Lührmann R, Fabrizio P. 2001. The yeast U5 snRNP coisolated with the U1 snRNP has an unexpected protein composition and includes the splicing factor Aar2p. RNA 7: 1554-1565.

Grainger RJ, Beggs JD. 2005. Prp8 protein: at the heart of the spliceosome. RNA 11: 533-557.

Kolb SJ, Battle DJ, Dreyfuss G. 2007. Molecular functions of the SMN complex. J Child Neurol 22: 990-994.

Liu S, Rauhut R, Vornlocher HP, Lührmann R. 2006. The network of protein-protein interactions within the human U4/U6. U5 tri-snRNP. RNA 12: 1418-1430.

Maeder C, Kutach AK, Guthrie C. 2009. ATP-dependent unwinding of U4/U6 snRNAs by the Brr2 helicase requires the C terminus of Prp8. Nat Struct Mol Biol 16: 42-48.

Makarov EM, Makarova OV, Urlaub H, Gentzel M, Will CL, Wilm M, Lührmann R. 2002. Small nuclear ribonucleoprotein remodeling during catalytic activation of the spliceosome. Science 298: 2205-2208.

Meinhart A, Cramer P. 2004. Recognition of RNA polymerase II carboxy-terminal domain by 3 '-RNA-processing factors. Nature 430: 223-226.

Misra S, Puertollano R, Kato Y, Bonifacino JS, Hurley JH. 2002. Structural basis for acidic-cluster-dileucine sorting-signal recognition by VHS domains. Nature 415: 933-937.

Nakazawa N, Harashima S, Oshima Y. 1991. AAR2, a gene for splicing pre-mRNA of the MATal cistron in cell type control of Saccharomyces cerevisiae. Mol Cell Biol 11: 56935700.

Nesic D, Tanackovic G, Krämer A. 2004. A role for Cajal bodies in the final steps of U2 snRNP biogenesis. J Cell Sci 117: 4423-4433.

Pandit S, Lynn B, Rymond BC. 2006. Inhibition of a spliceosome turnover pathway suppresses splicing defects. Proc Natl Acad Sci 103: 13700-13705.

Pena V, Liu S, Bujnicki JM, Lührmann R, Wahl MC. 2007. Structure of a multipartite protein-protein interaction domain in splicing factor prp8 and its link to retinitis pigmentosa. Mol Cell 25: 615-624.

Pena V, Rozov A, Fabrizio P, Lührmann R, Wahl MC. 2008. Structure and function of an RNase $\mathrm{H}$ domain at the heart of the spliceosome. EMBO I 27: 2929-2940.

Pena V, Jovin SM, Fabrizio P, Orlowski J, Bujnicki JM, Lührmann $\mathrm{R}$, Wahl MC. 2009. Common design principles in the spliceosomal RNA helicase Brr2 and in the Hel308 DNA helicase. Mol Cell 35: 454-466.

Pomeranz Krummel DA, Oubridge C, Leung AK, Li J, Nagai K. 2009. Crystal structure of human spliceosomal U1 snRNP at 5.5 A resolution. Nature 458: 475-480.

Raghunathan PL, Guthrie C. 1998. A spliceosomal recycling factor that reanneals U4 and U6 small nuclear ribonucleoprotein particles. Science 279: 857-860.

Ritchie DB, Schellenberg MJ, Gesner EM, Raithatha SA, Stuart DT, Macmillan AM. 2008. Structural elucidation of a PRP8 core domain from the heart of the spliceosome. Nat Struct Mol Biol 15: 1199-1205.

Shiba T, Takatsu H, Nogi T, Matsugaki N, Kawasaki M, Igarashi N, Suzuki M, Kato R, Earnest T, Nakayama K, et al. 2002. Structural basis for recognition of acidic-cluster dileucine sequence by GGA1. Nature 415: 937-941.

Small EC, Leggett SR, Winans AA, Staley JP. 2006. The EF-Glike GTPase Snu114p regulates spliceosome dynamics mediated by Brr2p, a DExD/H box ATPase. Mol Cell 23: 389399.

Staley JP, Guthrie C. 1998. Mechanical devices of the spliceosome: motors, clocks, springs, and things. Cell 92: 315-326.

van Nues RW, Beggs JD. 2001. Functional contacts with a range of splicing proteins suggest a central role for Brr2p in the dynamic control of the order of events in spliceosomes of Saccharomyces cerevisiae. Genetics 157: 1451-1467.

Verdone L, Galardi S, Page D, Beggs ID. 2004. Lsm proteins promote regeneration of pre-mRNA splicing activity. Curr Biol 14: 1487-1491.

Wahl MC, Will CL, Lührmann R. 2009. The spliceosome: design principles of a dynamic RNP machine. Cell 136: 701-718.

Weber G, Trowitzsch S, Kastner B, Lührmann R, Wahl MC. 2010. Functional organization of the $S m$ core in the crystal structure of human U1 snRNP. EMBO J 29: 4172-4184.

Xie J, Beickman K, Otte E, Rymond BC. 1998. Progression through the spliceosome cycle requires Prp38p function for U4/U6 snRNA dissociation. EMBO J 17: 2938-2946.

Yang K, Zhang L, Xu T, Heroux A, Zhao R. 2008. Crystal structure of the $\beta$-finger domain of Prp8 reveals analogy to ribosomal proteins. Proc Natl Acad Sci 105: 13817-13822.

Zhang L, Xu T, Maeder C, Bud LO, Shanks J, Nix J, Guthries C, Pleiss JA, Zhao R. 2009. Strutural evidence for consecutive Hel308-like modules in the spliceosomal ATPase Brr2. Nat Struct Mol Biol 16: 731-739.

Zhuo S, Clemens JC, Hakes DJ, Barford D, Dixon JE. 1993. Expression, purification, crystallization, and biochemical characterization of a recombinant protein phosphatase. J Biol Chem 268: 17754-17761. 


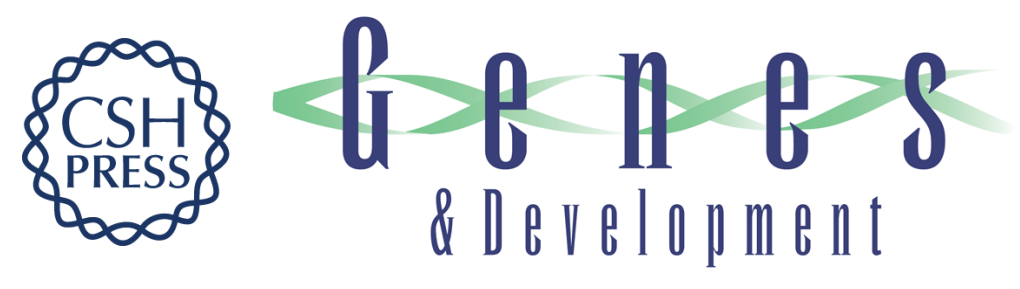

\section{Mechanism for Aar2p function as a U5 snRNP assembly factor}

Gert Weber, Vanessa F. Cristão, Flavia de L. Alves, et al.

Genes Dev. 2011, 25: originally published online July 15, 2011

Access the most recent version at doi:10.1101/gad.635911

\footnotetext{
Supplemental http://genesdev.cshlp.org/content/suppl/2011/07/07/gad.635911.DC1

Material

Related Content

A snRNP's ordered path to maturity

Saba Valadkhan

Genes Dev. August , 2011 25: 1563-1567

References This article cites 32 articles, 12 of which can be accessed free at: http://genesdev.cshlp.org/content/25/15/1601.full.html\#ref-list-1

Articles cited in:

http://genesdev.cshlp.org/content/25/15/1601.full.html\#related-urls

License Freely available online through the Genes \& Development Open Access option.
Email Alerting Receive free email alerts when new articles cite this article - sign up in the box at the top Service right corner of the article or click here.

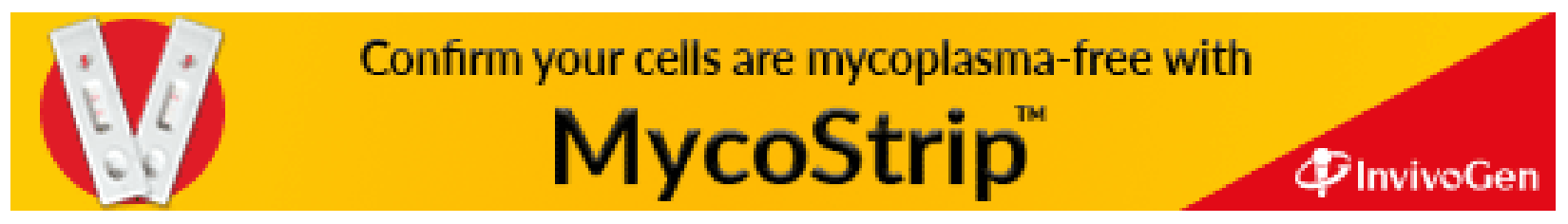

